\title{
Dynamic Model and Analysis of Nonlinear Vibration Characteristic of a Curve-Face Gear Drive
}

\author{
Zhiqin Cai - Chao Lin* \\ ${ }^{1}$ Chongqing University, The State Key Laboratory of Mechanical Transmission, China
}

To study the nonlinear dynamic characteristics of curve-face gear drive, a generalized nonlinear dynamic model based on Lagrange Bondgraphs was presented. The model considered the effects of the basic parameters of curve-face gear, such as meshing frequency, eccentricity $k$ and the order number $n_{1}$ of non-cylindrical gears. Utilizing this simulation model, the vibration characteristics of curve-face gears were analysed. It is indicated that the vibration response of the curve-face gear is more complex than that of the face gear due to the influence of external excitation. These characteristics determine that this gear pair cannot be applied directly to a transmission system with high speed. Finally, a related experiment was proposed to present the validation of the numerical model.

Keywords: curve-face gear, vibration response, limited speed, Lagrange bond-graphs, time-varying characteristics

Highlights

- A nonlinear dynamic model based on a Lagrange bond-graph was presented. The proposed method not only applies to the dynamic analysis of curve-face gears but also can be applied to face gears.

- $\quad$ The research results show that $r b_{1}$ and $R$ are the main factor affecting the vibration response of curve-face gear, and reducing the eccentricity $k$ and raising the order $n_{1}$ will improve the dynamic characteristics.

- Due to the influence of external excitation, which will exacerbate the vibration, the limited meshing frequency of curve-face gears is lower than face gears. These characteristics determine that the gear cannot be applied to a transmission system with high speed.

\section{O INTRODUCTION}

As a new type of face gear, curve-face gear combines the common characteristics of non-cylindrical gear, bevel gear, and face gear [1]. It can be used in engineering machinery, agricultural machinery, textile machinery and high-powered spacecraft, etc. [2], and will be developed towards high speeds and heavy loads [3]. Therefore, the research on the dynamic characteristics of curve-face gear has increasingly become prominent.

The research of the nonlinear vibration characteristics of gears mainly focuses on the bevel gear, spur gear, face gear and planetary gear drive; the analytical approach of the system generally uses finite element method (FEM), and the Runge-Kutta method is applied to solve the differential equations of the system. For the simulation and vibration-based condition monitoring of a geared system, a system with an appropriate number of degrees of freedom (DOFs) was modelled [4]. An investigation of the performance of statistical fault detection indicators for three different series of crack propagation scenarios was presented [5]. From the vibration signal, the numbers of teeth on all gears, the calculation of tooth mesh frequencies and rotational speeds of all shafts were determined [6]. The dynamic behaviour of a single-stage spur gear reducer in a transient regime was studied [7]. However, for the rotary system with mass eccentricity, the Lagrange equation with generalized coordinates expression is over FEM, as it only relates to the kinetic energy and the potential energy of the system. Therefore, for the mechanical system composed of particles and rigid bodies, the system equation can be obtained quickly by using the Lagrange equation. However, due to the differential calculation of Lagrange function $L$, its simulation process is complex. To overcome the disadvantage of this modelling method, a new modelling method combined Lagrange equation and bond-graph is proposed. When the generalized coordinates, the parameter equation, the force input, and the velocity conversion matrix are determined, the mathematical simulation of the system can be obtained. Compared with the classical method, the modelling process of the Lagrange bond-graph is more regular, and the solving process is more efficient [8].

Recently, few studies were available for the curve-face gear drive. Due to the time-varying characteristics of non-circular gears, the vibration response of this type of gear is much complex than that of normal gears. For general gears, the excitations of the vibration response are mainly time-varying mesh stiffness, tooth transmission error, and meshing impact, etc. The dynamic model of a spur gear pair, considering the backlash, time-varying stiffness, 
and static transmission error, was established [9]. Using standard methods for nonlinear systems, the dynamics of gear systems with various faults in meshing stiffness was examined [10]. Considering time-varying mesh stiffness, mesh damping, tooth error, tooth friction, backlash and bearing clearance, a bending-torsion coupled nonlinear dynamic model of a face-gear drive system was established [11]. A nonlinear dynamic model of a face gear system was presented by the concentrated parameters, gear clearances, transmission error, meshing stiffness, meshing damping, brace stiffness, support damping and exciting frequency [12]. However, for a noncircular gear, in addition to the above factors, the regular external excitation, caused by the basic parameters of the non-circular gear, such as meshing frequency, eccentricity $k$ and the order $n_{1}$ of the noncylindrical gear, is one of the main influencing factors. For the vibration response of the non-circular gear, a dynamic model of a non-cylindrical gear based on the Lagrange bond-graphs theory was established [13]. A virtual experimental model of the non-cylindrical gear was established, and the corresponding dynamic response was obtained [14]. Considering the timevarying meshing stiffness, a tensional vibration model of a non-circular gear was developed [15]. Bearing in mind input shaft and output shaft excitation, the time-varying meshing stiffness, static transmission error, gear backlash, a nonlinear dynamic model of the twisting vibration of the curve-face gear was established [16]. However, the systematic analysis of the effect of the basic parameters of curve-face gear on the vibration response remain unknow, and the phenomenon of the limited speed of curve-face gear is not yet analysed.

In this paper, a generalized nonlinear dynamic model of curve-face gear based on Lagrange bondgraph was proposed, and the related vibration responses were analysed using bond-graph theory. With the change of meshing frequency, eccentricity $k$ and the order $n_{1}$ of non-circular gear, different vibration responses were shown in the "time history chart" and "phase diagram". Finally, a related experiment was proposed to verify the correctness of the theoretical mode.

\section{VIBRATION MODEL REVIEW}

The meshing process of the curve-face gear pair is illustrated as shown in Fig. 1. Coordinates $S_{1}\left(X_{1} Y_{1} Z_{1}\right)$ and $S_{2}\left(X_{2} Y_{2} Z_{2}\right)$ are fixed on the frame of the noncylindrical gear and the curve-face gear. The noncylindrical gear and the curve-face gear rotate along their own axis $O_{1} Z_{1}$ and axis $O_{2} Y_{2}$ with rotation angles $\theta_{1}$ and $\theta_{2}$, respectively.

According to the characteristics of the curveface gear, the meshing force can be decomposed into forces along the direction of axis $X_{2}$ and axis $Y_{2}$, and there is no radial force. Compared with the bevel gear, the supporting structure of the curve-face gear pair is relatively simple, and the DOFs of vibration are less.

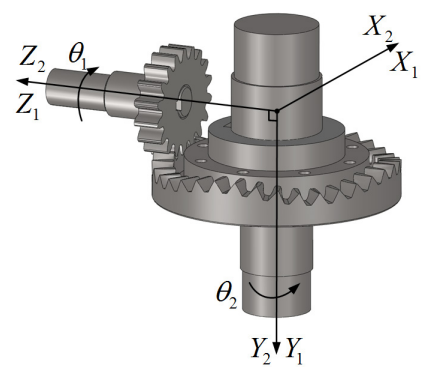

Fig. 1. Modelling of curve-face gear drive

The transmission ratio of curve-face gear drive and can be expressed as:

$$
i_{12}=\frac{R}{r\left(\theta_{1}\right)} \text {. }
$$

The value of cylindrical radius $R$ and polar radius $r\left(\theta_{1}\right)$ of non-cylindrical gear can be represented as:

$$
\left\{\begin{array}{l}
r\left(\theta_{1}\right)=\frac{1-k \cos \left(n_{1} \theta_{1}\right)}{a\left(1-k^{2}\right)} \\
R=\frac{n_{2}}{2 \pi} \int_{0}^{\frac{2 \pi}{n_{1}}} r\left(\theta_{1}\right) \mathrm{d} \theta_{1}
\end{array} .\right.
$$

\subsection{Method of Lagrange Bond-Graph}

With the complexity of system increases, the conventional method establishing the nonlinear vibration model is quite tedious. Especially for curveface gear drives, the influence of eccentric mass must be considered [13]. Although the modelling process by the Lagrange equation, based on kinetic energy and potential energy can be easier, the solving process remaining difficult. To overcome this disadvantage, combining with the method of bond-graph, the system equation and the calculation process can be easier. A basic Lagrange bond-graph model is shown in Fig. 2, $X$ represents the field source, such as damping filed $R$, Inertial field - $I$ and elastic field - $K$, etc. " 1 " port link the serial energy ports. MIF represents the matrix transformation $T_{X} \cdot \dot{q}_{G}$ is the generalized velocity vector which is the first order derivative of generalized displacement $q_{G} \cdot F_{X}$ represents the corresponding 
force, such as the D 'Alembert force $F_{I}$, elastic force $F_{K / k}$, dissipative force $F_{R / r}$ and input force $F_{S}$.

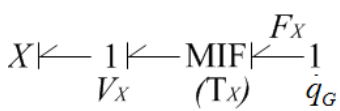

Fig. 2. Basic Lagrange bond-graph model

$V_{X}$ is the velocity vector which can be expressed as:

$$
V_{X}=T_{X} \cdot \dot{q}_{G} .
$$

In this paper, a generalized nonlinear model based on the Lagrange bond-graph is proposed as shown in Fig. 3.

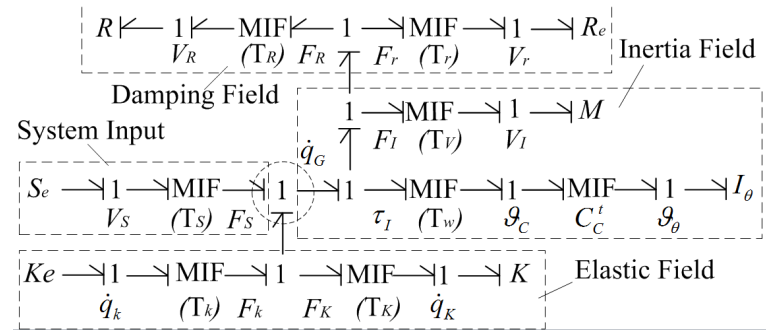

Fig. 3. Lagrange bond-graph model of system

In Fig. 3, "1" port links the serial energy ports. Each leg (force) has a contribution in "1" port.

$$
F_{I}+\tau_{I}+F_{K}+F_{R}=F_{S}+F_{k}+F_{r} .
$$

The hidden dynamic equation of the Lagrange bond-graph model is represented as follows:

$$
\begin{gathered}
T_{I}{ }^{t} I\left(T_{I} \frac{d^{2} q_{G}}{d t^{2}}+\frac{d T_{I}}{d t} \frac{d q_{G}}{d t}\right)+T_{W}{ }^{t} C_{C} \frac{d C_{C}^{t}}{d t} I_{C} \cdot T_{W} \frac{d q_{G}}{d t}+ \\
+T_{K}{ }^{t} K f\left(q_{G}\right)+T_{R}{ }^{t} \operatorname{Rg}\left(q_{G}\right)= \\
=T_{S}{ }^{t} \tau_{S}+T_{k}^{t} K_{e} e_{t}+T_{r}^{t} R_{e} \frac{d e_{t}}{d t} .
\end{gathered}
$$

\subsection{Derivation of Dynamic Model}

The dynamic model of a curve-face gear drive is shown in Fig. 4. $Z_{1}$ and $Y_{2}$ are rotational axes of the non-cylindrical gear and curve-face gear, respectively. The value of basic parameters, meshing stiffness $k_{i}$, damping $c_{i}\left(i=x_{1}, x_{2}, y_{1}, y_{2}, m\right)$, and torque $T_{j}(j=1,2)$ are shown in Table 1.

\subsubsection{Determination of Key Vectors}

The displacement vector in generalized coordinates can be represented as:

$$
q_{G}=\left[\begin{array}{llllll}
X_{1} & Y_{1} & \theta_{1} & X_{2} & Y_{2} & \theta_{2}
\end{array}\right]^{t},
$$

and the displacement vector in elastic field can be defined as:

$$
q_{K}=\left[\begin{array}{llllll}
X_{1} & Y_{1} & c_{1} X_{n} & X_{2} & Y_{2} & c_{2} X_{n}
\end{array}\right]^{t},
$$

where $c_{1}=\cos a_{n}, c_{2}=\sin a_{n}$.

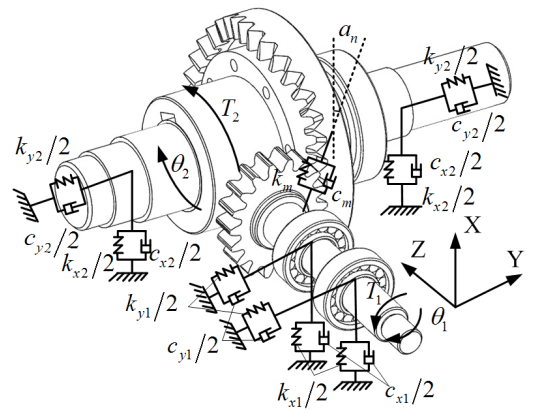

Fig. 4. Dynamic model of curve-face gear drive system

Input force vector $\tau_{S}$ can be defined as:

$$
\tau_{S}=\left[\begin{array}{llllll}
0 & 0 & T_{1} & 0 & 0 & -T_{2}
\end{array}\right]^{t} .
$$

Gear comprehensive error vector can be defined as:

$$
e_{t}=\left|e_{t}\right| \cdot\left[\begin{array}{lll}
1 & \ldots & 1
\end{array}\right]_{1 \times 6}^{t}
$$

For the cylindrical gear drive, the pressure angle is equal to the gear shaper. However, this is not so for the curve-face gear pair.

As shown in Fig. 5, $L_{1}$ as $1, L_{2}$ as 2 and $L_{3}$ as 3 are the pitch curve of the non-cylindrical gear, curveface gear and gear shaper, respectively. Three tooth profiles $G_{1}, G_{2}$ and $G_{3}$ are in tangency at point $P$.

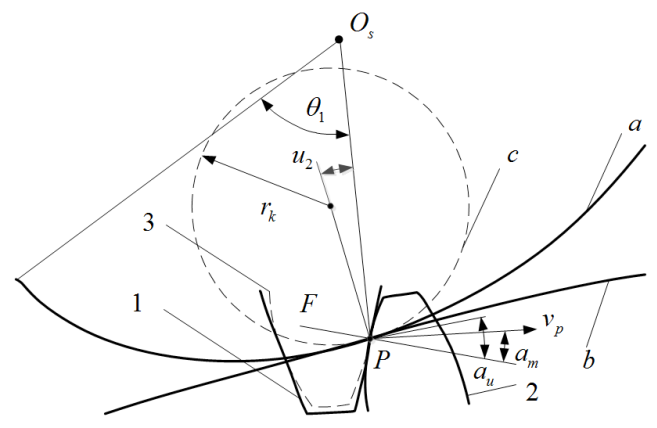

Fig. 5. Pressure angle of curve-face gear drive

According to the definition of pressure angle, the pressure angle $\alpha_{u}$ of the gear shaper is constant. However, the pressure angle $\alpha_{n}$ of the curve-face gear 
refers to the angle between absolute velocity $v_{p}$, and the normal force $F$ which can be obtained as:

$$
\alpha_{n}=\alpha_{u}+\frac{\pi}{2}-\arctan r\left(\theta_{1}\right) / \dot{r}\left(\theta_{1}\right) .
$$

Set $X_{n}$ as the static transmission error.

$$
X_{n}=c_{1}\left(X_{1}+r_{b 1} \theta_{1}\right)+c_{2} Y_{1}-c_{1}\left(X_{2}+R \theta_{2}\right)-c_{2} Y_{2} \text {. }
$$

However, in the actual condition, gear backlash $2 b$ is an important nonlinear factor of gear dynamics, which can be expressed as:

$$
f(x)= \begin{cases}X_{n}-b & X_{n}>b \\ 0 & \left|X_{n}\right| \leq b . \\ X_{n}+b & X_{n}<-b\end{cases}
$$

\subsubsection{Determination of Transform Matrix}

The curve-face gear drive is a complex transmission system composed of multiple rigid bodies. The comprehensive velocity transform matrix in an inertial field can be expressed as:

$$
T_{I}=\left[\frac{T_{V}}{T_{W}}\right] .
$$

Moreover, velocity transform matrix in a potential source field can be expressed as:

$$
T_{S}=E_{(6 \times 6)} .
$$

Velocity transform matrix in a damping field can be expressed as:

$$
T_{R}=\left[\begin{array}{cccccc}
1 & 0 & 0 & 0 & 0 & 0 \\
0 & 1 & 0 & 0 & 0 & 0 \\
c_{1}^{2} & c_{1} c_{2} & c_{1} r_{b 1} & -c_{1}^{2} & -c_{1} c_{2} & -c_{1} R \\
0 & 0 & 0 & 1 & 0 & 0 \\
0 & 0 & 0 & 0 & 1 & 0 \\
c_{1} c_{2} & c_{2}^{2} & c_{1} r_{b 1} & -c_{1} c_{2} & -c_{2}^{2} & -c_{2} R
\end{array}\right] .
$$

When taking in account the gear comprehensive error, the velocity transform matrix in a damping field can be expressed as:

$$
\mathrm{T}_{r}=\operatorname{diag}\left(\begin{array}{llllll}
1 & 1 & r_{b 1} & -1 & -1 & -R
\end{array}\right) .
$$

The velocity transform matrix in an elastic field can be expressed as:

$$
T_{K}=T_{R} .
$$

Similarly, the velocity transform matrix in an elastic field, considering the gear comprehensive error, can be defined as:

$$
T_{k}=\operatorname{diag}\left(\begin{array}{llllll}
1 & 1 & r_{b 1} & -1 & -1 & -R
\end{array}\right) .
$$

The rotation matrix can be expressed as:

$$
C_{C}=\left[\begin{array}{cccccc}
\cos \theta_{1} & \sin \theta_{1} & 0 & 0 & 0 & 0 \\
-\sin \theta_{1} & \cos \theta_{1} & 0 & 0 & 0 & 0 \\
0 & 0 & 1 & 0 & 0 & 0 \\
0 & 0 & 0 & \cos \theta_{2} & \sin \theta_{2} & 0 \\
0 & 0 & 0 & -\sin \theta_{2} & \cos \theta_{2} & 0 \\
0 & 0 & 0 & 0 & 0 & 1
\end{array}\right],
$$

\subsubsection{Determination of Boundary Conditions}

The boundary conditions of curve-face gear drive are represented as follows:

a) Damping field

The damping matrix in a damping field can be expressed as:

$$
R=\operatorname{diag}\left(\begin{array}{cccccc}
c_{x_{1}} & c_{y_{1}} & c_{m} & c_{x_{2}} & c_{y_{2}} & c_{m}
\end{array}\right) .
$$

Similarly, when taking into account gear comprehensive error, it can be defined as:

$$
R_{e}=\operatorname{diag}\left(\begin{array}{cccccc}
c_{x} & c_{y} & c_{m} & c_{x} & c_{y} & c_{m}
\end{array}\right),
$$

where $c_{x}=c_{1} c_{m}, c_{y}=c_{2} c_{m}$.

b) Inertial field

The mass matrix in an inertial field can be expressed as:

$$
\mathrm{I}=\left[\begin{array}{c:c}
\mathrm{M} & 0 \\
\hdashline 0 & \mathrm{I}_{C}
\end{array}\right]
$$

c) Elastic field

The stiffness matrix in a damping field can be expressed as:

$$
K=\operatorname{diag}\left(k_{x_{1}} \quad k_{y_{1}} \quad k_{m} \quad k_{x_{2}} \quad k_{y_{2}} \quad k_{m}\right) .
$$

Similarly, when considering gear comprehensive error, it can be defined as:

$$
K_{e}=\operatorname{diag}\left(k_{x} \quad k_{y} \quad k_{m} \quad k_{x} \quad k_{y} \quad k_{m}\right),
$$

where $k_{x}=c_{1} k_{m}, k_{y}=c_{2} k_{m}$.

\subsubsection{Determination of System Equation}

Substituting Eqs. (6) to (24) into Eq. (5), the dynamic nonlinear differential equations can be expressed as:

$$
\left.\begin{array}{l}
m_{1} \ddot{X}_{1}+c_{x_{1}} \dot{X}_{1}+k_{x_{1}} X_{1}+c_{1} k_{m} \delta_{n}=-c_{m} c_{1} \dot{\delta}_{n} \\
m_{1} \ddot{Y}_{1}+c_{y_{1}} \dot{Y}_{1}+k_{y_{1}} Y_{1}+c_{2} k_{m} \delta_{n}=-c_{m} c_{2} \dot{\delta}_{n} \\
I_{z_{1} z_{1}} \ddot{\theta}_{1}+k_{m} \delta_{n} r_{b 1}=T_{1}-c_{m} \dot{\delta}_{n} r_{b 1} \\
m_{2} \ddot{X}_{2}+c_{x_{2}} \dot{X}_{2}+k_{x_{2}} X_{2}-c_{1} k_{m} \delta_{n}=-c_{m} c_{1} \dot{\delta}_{n} \\
m_{2} \ddot{Y}_{2}+c_{y_{2}} \dot{Y}_{2}+k_{y_{2}} Y_{2}-c_{2} k_{m} \delta_{n}=c_{m} c_{2} \dot{\delta}_{n} \\
I_{z_{2} z_{2}} \ddot{\theta}_{2}-k_{m} \delta_{n} R=-T_{2}+c_{m} \dot{\delta}_{n} R
\end{array}\right\}
$$


where $\delta_{n}=X_{n}-e(t), \dot{\delta}_{n}=\dot{X}_{n}-\dot{e}(t)$.

\section{VIBRATION EXCITATION OF SYSTEM}

\subsection{Stiffness}

Meshing stiffness is composed of the average stiffness $k_{m m}$ and time-varying stiffness.

$$
k_{m}(t)=k_{m m}+\sum_{i=1}^{n} k_{i} \cos \left(i \Omega_{h} t-\varphi_{i}\right) .
$$

The value of $k_{i}(t)$ is associated with contact ratio $\varepsilon$ and can be expressed as:

$$
\left\{\begin{array}{l}
k_{i}(t)=\frac{\sqrt{2-2 \cos \left(2 \pi i\left(\varepsilon_{m}-m\right)\right)}}{i \pi} k_{p} \\
\varphi_{i}=\arctan \frac{1-\cos \left(2 \pi i\left(\varepsilon_{m}-m\right)\right)}{\sin \left(2 \pi i\left(\varepsilon_{m}-m\right)\right)} \\
k_{p}=k_{m m} / \varepsilon_{m}
\end{array},\right.
$$

where $\varepsilon_{m}$ fits the monogenic harmonic function, which can be obtained as:

$$
\varepsilon_{m}\left(\theta_{1}\right)=\varepsilon_{m m}+\sum_{i=1}^{n} \varepsilon_{i} \cos \left(i \theta_{1}-\sigma_{i}\right) .
$$

As the stiffness of the bearing is highly sensitive to the load on the bearing in the radial direction, the selection of the adopted bearing stiffness is necessary. As a kind of non-circular gear, the curve-face gear is mainly applied in medium-low speed and lowload occasions. Specifically, the change of load has little effect on the stiffness. In this paper, the bearing stiffness is regarded as a constant, which can be obtained as:

$$
k=\lim _{\substack{\Delta F_{r} \rightarrow 0 \\ \Delta \delta \rightarrow 0}} \frac{\Delta F_{r}}{\Delta \delta}=\frac{1}{n+m+m \ln F_{r}+0.13 C F_{r}^{-1.13}},
$$

where the basic parameters $m, n, C$ and $F_{r}$ can be obtained from the reference [17].

\subsection{The Driving Torque}

Although the driving torque $T_{2}$ is constant, the driven torque $T_{1}$ of the curve-face gear is variable due to the time-varying transmission ratio. The relationship between the driving torque $T_{2}$ and the driven torque $T_{1}$ can be expressed as:

$$
T_{1}=\left(T_{2}-I_{2} \alpha_{2}\right) / i_{12},
$$

where angular acceleration $a_{2}$ can be described as:

$$
\alpha_{2}=\frac{d \omega_{2}}{d t}=\frac{n_{1} a \omega_{1}^{2} k\left(1-k^{2}\right) \sin \left(n_{1} \omega_{1} t\right)}{R\left(1-k \cos \left(n_{1} \omega_{1} t\right)\right)^{2}} .
$$

The equivalent excitation force can be described as:

$$
F_{m}(t)=\frac{T_{1} I_{z 2 z 2} r_{b 1}\left(\theta_{1}\right)+I_{z 1 z 1} R\left(T_{2}-I_{2} \alpha_{2}\right)}{I_{z 1 z 1} R^{2}+I_{z 2 z 2} r_{b 1}^{2}\left(\theta_{1}\right)} .
$$

\section{DIMENSIONLESS DYNAMIC EQUATION}

For curve-face gear, the value of $r\left(\theta_{1}\right)$ varies with the rotation angle $\theta_{1}$. That is, the base radius $r_{b 1}$ of the non-cylindrical gear is not constant and the velocity of the static transmission error can be calculated as:

$$
\begin{aligned}
\dot{X}_{n} & =\left(\dot{X}_{1} \cos a_{n}+\dot{r}_{b 1} \theta_{1}+r_{b 1} \dot{\theta}_{1}\right)+\dot{Y}_{1} \sin a_{n}- \\
& -\left(\dot{X}_{2} \cos a_{n}+R \dot{\theta}_{2}\right)-\dot{Y}_{2} \sin a_{n} .
\end{aligned}
$$

Let $\quad \omega_{n}=\sqrt{k_{m m} / m_{e}}, \quad \tau=\omega_{n} t, \quad \omega_{h}=\Omega_{h} / \omega_{n} ;$ $x_{j}=X_{j} / b_{m} ; y_{j}=Y_{j} / b_{m} ; \lambda_{n}=X_{n} / b_{m}-e(\tau) ; \vartheta_{j}=\theta_{j} / b_{m}$ and $e(\tau)=\left(e_{0}+e_{r} \cos \left(\omega_{h} \tau+\phi_{i}\right)\right) / b_{m}$.

Then, Eq. (25) can be dimensionless as:

$$
\left.\begin{array}{l}
\ddot{x}_{1}+2 \zeta_{x_{1}} \dot{x}_{1}+2 c_{1} \zeta_{m 1} \dot{\lambda}_{n}+\kappa_{x_{1}} x_{1}+c_{1} \kappa_{m 1} \lambda_{n}=0 \\
\ddot{y}_{1}+2 \zeta_{y_{1}} \dot{y}_{1}+2 c_{2} \zeta_{m 1} \dot{\lambda}_{n}+\kappa_{y_{1}} y_{1}+c_{2} \kappa_{m 1} \lambda_{n}=0 \\
\ddot{\vartheta}_{1}+2 r_{b 1} \zeta_{h 1} \dot{\lambda}_{n}+r_{b 1} \kappa_{h 1} \lambda_{n}=\xi_{1} \\
\ddot{x}_{2}+2 \zeta_{x_{2}} \dot{x}_{2}-2 c_{1} \zeta_{m 2} \dot{\lambda}_{n}+\kappa_{x_{2}} x_{2}-c_{1} \kappa_{m 2} \lambda_{n}=0 \\
\ddot{y}_{2}+2 \zeta_{y 2} \dot{y}_{2}-2 c_{2} \zeta_{m 2} \dot{\lambda}_{n}+\kappa_{y_{2}} y_{2}-c_{2} \kappa_{m 2} \lambda_{n}=0 \\
\ddot{\vartheta}_{2}-2 R \zeta_{h 2} \dot{\lambda}_{n}-R \kappa_{h 2} \lambda_{n}=-\xi_{2}
\end{array}\right\},
$$

where $\omega_{i j}=\sqrt{k_{i j} / m_{j}} ; \zeta_{i j}=c_{i j} /\left(2 m_{j} \omega_{n}\right)$; $\zeta_{m j}=c_{m} /\left(2 m_{j} \omega_{n}\right) ; \kappa_{m j}=k_{m}(\tau) /\left(2 m_{j} \omega_{n}\right)$; $\kappa_{h j}=k_{m}(\tau) /\left(2 I_{j} \omega_{n}\right) ; \kappa_{i j}=\omega_{i j}^{2} / \omega_{n}^{2} ; \zeta_{h j}=c_{m} /\left(2 I_{j} \omega_{n}\right)$; $(i=x, y, j=1,2)$.

\section{SIMULATION AND ANALYSIS}

As can be seen in Eq. (34), it is a higher-order nonlinear vibration system. In this paper, the bond-graph method was introduced to solve the dimensionless dynamic of differential equations. When the generalized coordinates, the parameter equation, the force input and the velocity conversion matrix (Eqs. (6) to (24)) are determined, the time history chart and phase diagram can be obtained, and the results are presented in the dimensionless form.

Due to the external excitation of the curve-face gear pair caused by eccentricity $k$, meshing frequency 
$\omega_{h}$ and order $n_{1}$ of the non-cylindrical gear, a unique dynamic characteristic of curve-face gear system is produced as shown in Figs. 6 to 8 .

Table 1. Basic parameters of curve-face gear drive

\begin{tabular}{|c|c|}
\hline Parameters & Curve-face gear \\
\hline Module $m$ [mm] & 4 \\
\hline Teeth of driving gear $z_{1}$ & 18 \\
\hline Teeth of driven gear $z_{2}$ & 36 \\
\hline Tooth width $B$ [mm] & 30 \\
\hline Driven torque [Nm] & 700 \\
\hline Weight of drive gear $m_{1}[\mathrm{~kg}]$ & 0.515 \\
\hline Weight of driven gear $m_{2}[\mathrm{~kg}]$ & 1.673 \\
\hline Rotational inertia $I_{z 1 z 1}\left[\mathrm{~kg} \cdot \mathrm{m}^{2}\right]$ & $3.5 \times 10^{-4}$ \\
\hline Rotational inertia $I_{z 2 z 2}\left[\mathrm{~kg} \cdot \mathrm{m}^{2}\right]$ & $8.1 \times 10^{-3}$ \\
\hline Meshing rigidity $k_{m m}[\mathrm{~N} \cdot \mathrm{m}-1]$ & $8.1 \times 10^{8}$ \\
\hline Meshing damping $c_{m}\left[\mathrm{~N} \cdot \mathrm{s} \cdot \mathrm{m}^{-1}\right]$ & $2.5 \times 10^{3}$ \\
\hline Support stiffness $k\left[\mathrm{~N} \cdot \mathrm{m}^{-1}\right]$ & $\begin{array}{l}k_{x 1}=7.41 \times 10^{8} ; k_{x 2}=1.2 \times 10^{9} \\
k_{y 1}=6.48 \times 10^{8} ; k_{y 2}=1.13 \times 10^{9}\end{array}$ \\
\hline Support damping $c\left[\mathrm{~N} \cdot \mathrm{s} \cdot \mathrm{m}^{-1}\right]$ & $\begin{array}{l}c_{x 1}=2.26 \times 10^{3} ; c_{x 2}=1.6 \times 10^{4} \\
c_{y 1}=2.11 \times 10^{3} ; c_{y 2}=1.55 \times 10^{4}\end{array}$ \\
\hline
\end{tabular}

\subsection{Dynamic Results by Eccentricity}

Eccentricity $k$ is one of the main parameters that reflects the vibration response of the curve-face gear drive. Fig. 6 gives the results of gear vibration response in different eccentricity $k$.

Referring to 'time history chart' (Fig. 6), when the meshing frequency is constant, the number of vibration periods remains unchanged with eccentricity $k$. With the increase of eccentricity $k$, the vibration amplitude increases and the vibration period converts from harmonic-periodic to quasi-periodic motion. The main cause for this phenomenon depends on:

1) According to Eq. (34), $r_{b 1}$ and $R$ are the main factors affecting the vibration response of the system. For the curve-face gear, $r_{b 1}$ changes accordingly with the change of meshing frequency, which is different from the ordinary gear. This leads to a regular fluctuation of the normal load (or eccentric load) under the same load torque with the external excitation changes.

2) In addition to the influence of the meshing frequency, $r_{b 1}$ and $R$ are also affected by eccentricity $k$ and the order number $n_{1}$ of noncylindrical gear. The fluctuating range of $r_{b 1}$ increases but the value of $R$ decreases with the rise of eccentricity $k$, which results in the increase of external excitation and the intention of vibration.

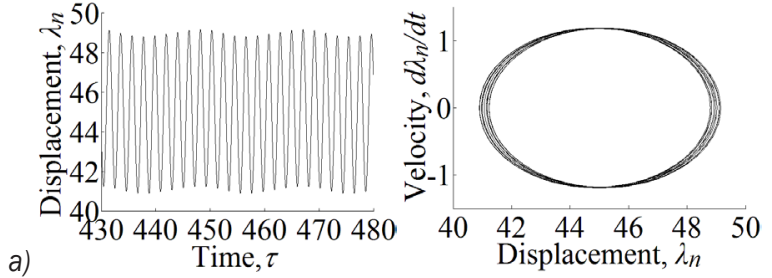

a)
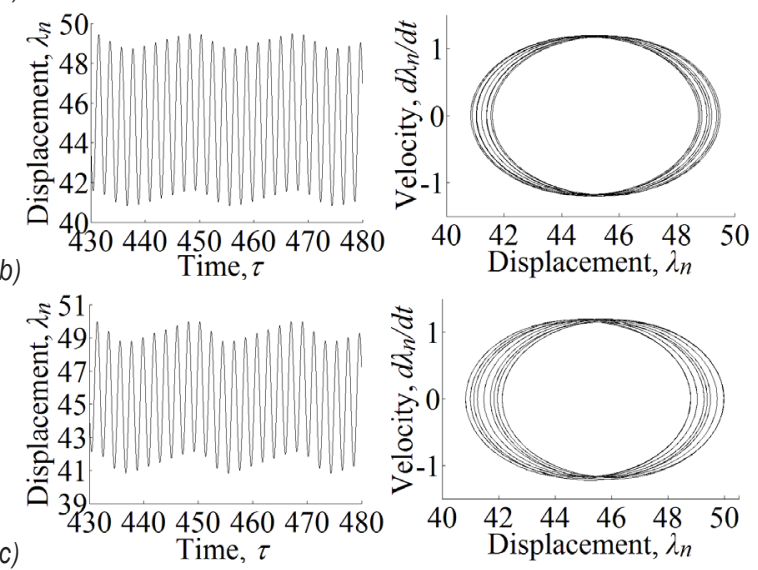

Fig. 6. Influence of eccentricity on system response; time history chart and phase diagram for a) eccentricity $k=0.1, b$ ) eccentricity $k=0.2$, and $c$ ) eccentricity $k=0.3$

As shown in the phase diagram (Fig. 6), the equilibrium positions of the curve-face gear shift backwards and forwards in the process of vibration: the equilibrium positions of vibration vary periodically with meshing time, and the value of the vibration amplitude rises with the increase of eccentricity $k$. The main reason is that the normal load (or eccentric load) between the tooth is affected by $r_{b 1}$ and $R$. Under the excitation of meshing stiffness, the vibration displacement changes and thus the deviation of the equilibrium position changes correspondingly.

In conclusion, the dynamic performance tends to be better with the decrease of eccentricity $k$.

\subsection{Dynamic Results by the Order $k_{1}$}

As another significant factor of the vibration response of the curve-face gear drive, the different order number $n_{1}$ of non-cylindrical gear determine different dynamic performances as shown in Fig. 7.

As shown in the 'time history chart' (Fig. 7), when the meshing frequency is constant, the number of vibration periods remains unchanged with the order number $n_{1}$ of non-cylindrical gears. With the increase of the order number $n_{1}$, the vibration amplitude decreases and the fluctuation period increases from 1 to 3. The main reasons are as follows: 
1) The change period of $r_{b 1}$ increases, and the amplitude remains unchanged, which leads to the increase of the fluctuation period of vibration;

2) The vibration amplitude decreases as the value of $R$ increases and the order number $n_{1}$ increases.

As shown in the phase diagram (Fig. 7), the periodic change and main reason of the equilibrium positions are the same as in Fig. 6. However, the deviation of the equilibrium position remains constant and the number of the equilibrium positions decreases due to the changing rules of $r_{b 1}$.
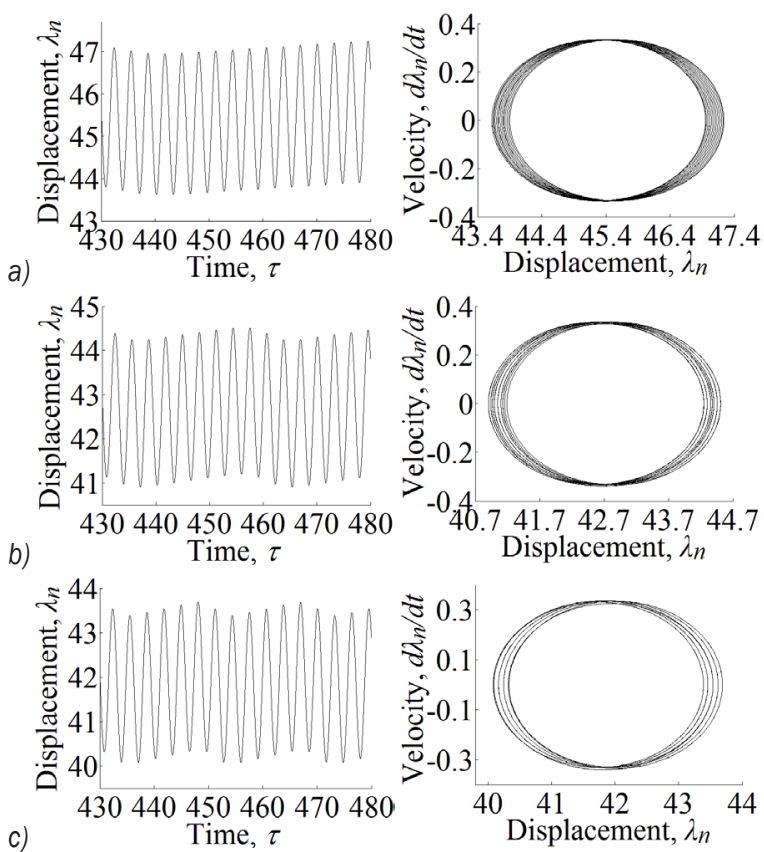

Fig. 7. Influence of order on system response, time history chart, and phase diagram for: a) order $\left.n_{1}=1, b\right)$ order $n_{1}=2$ and

$$
\text { c) order } n_{1}=3
$$

In conclusion, the dynamic performance tends to be better with the increase of the order $n_{1}$.

\subsection{Dynamic Results by Meshing Frequency}

For various meshing frequencies, the dynamic response of curve-face gear drive shows different fluctuation amplitudes and equilibrium positions.

As shown in Fig. 8, when the meshing frequency increases, eccentricity $k$ and the order number $n_{1}$ are constant:

1) The number of vibration periods, the equilibrium positions and the vibration amplitude all increase, which is the same as the vibration of the face gear [11];
2) The equilibrium positions vary periodically with meshing frequency since $r_{\mathrm{b} 1}$ changes accordingly with the change of meshing frequency.

For the vibration response of curve-face gear, while the meshing frequency increases, the change of value $r_{\mathrm{b} 1}$ affects the external excitation, inertia force and centrifugal force, which intensifies the vibration of the system. Consequently, the vibration performance of the curve-face gear is more complex than that of the face gear.

In this situation, both sides of the tooth surface will contact alternatively when the meshing frequency reaches a certain value. This is not allowed in the vibration response of the gear transmission system, which results in a limited meshing frequency of the curve-face gear.
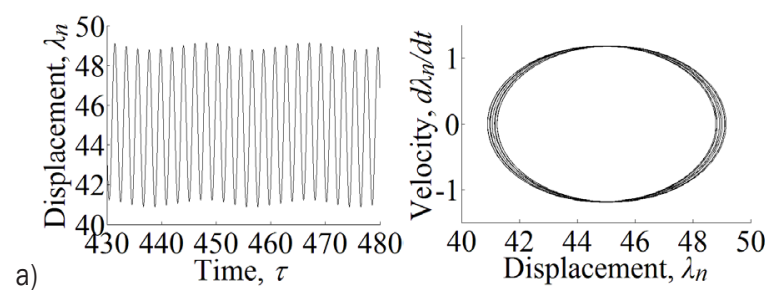

a)
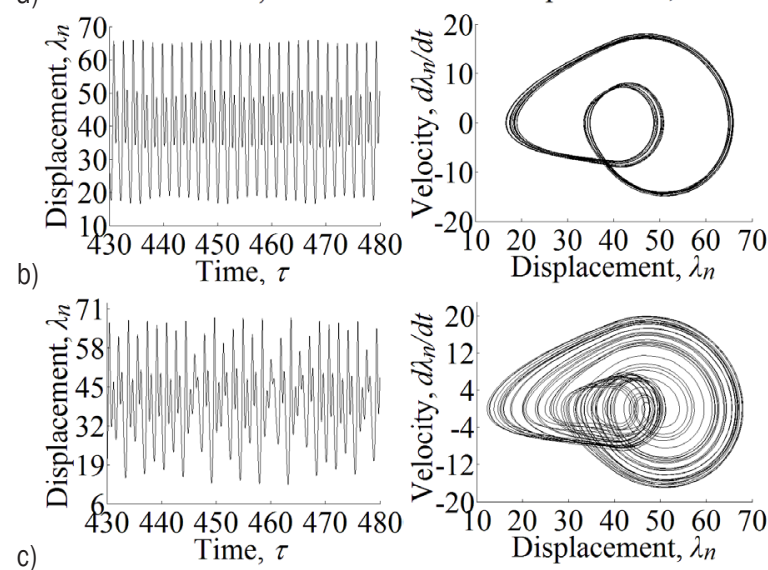

Fig. 8. Influence of meshing frequency on system response; time history chart and phase diagram for dynamic response when a) $\omega_{h}=0.3$, b) $\omega_{h}=0.35$ and c) $\omega_{h}=0.3591$
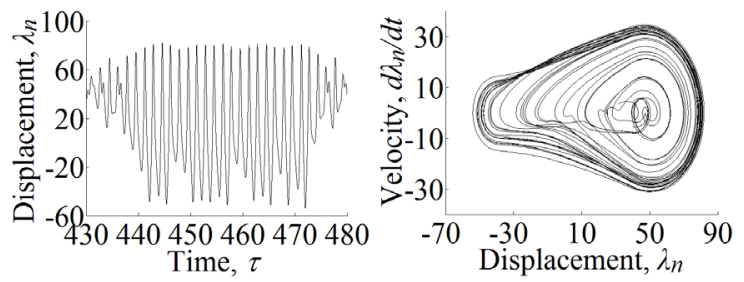

Fig. 9. Dynamic response under limited speed; time history chart and phase diagram

As shown in Fig. 9, when the meshing frequency is 0.378 , the reverse contact appears. This reveals that 
the gear will not work properly since the meshing frequency reaches the limited value. The meshing frequency can be converted to a limited speed of $790 \mathrm{rpm}$, which indicates that the curve-face gear is suitable for medium and low speed situations.

\section{VALIDATION AND ANALYSIS}

\subsection{Theory Validation}

When $k=0$, the curve-face gear can be degenerated into an ideal face gear. A harmonic response is shown by the time history chart and phase diagram (Fig. 10), which is the same as the existing conclusion of face gear [11]. This means that the dynamic equation not only can be applied to the dynamic analysis of curveface gear, but also to face gear.
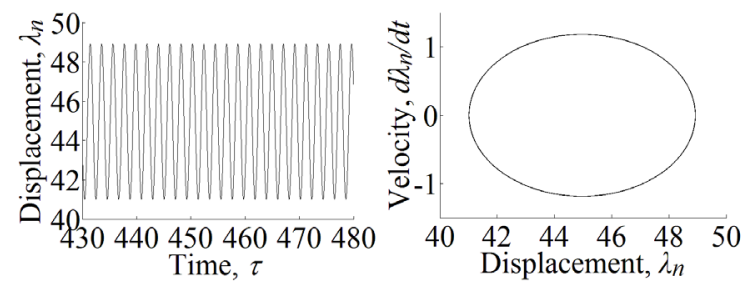

Fig. 10. Theory validation, time history chart, and phase diagram

The root cause lies in the fact that there is no essential difference between non-circular gears and conventional gears except for the difference of transmission ratio function. Thus, the impact of external excitation no longer exists.

\subsection{Experiment Validation}

The experiment is based on the transmission platform of the curve-face gear as shown in Fig. 11.

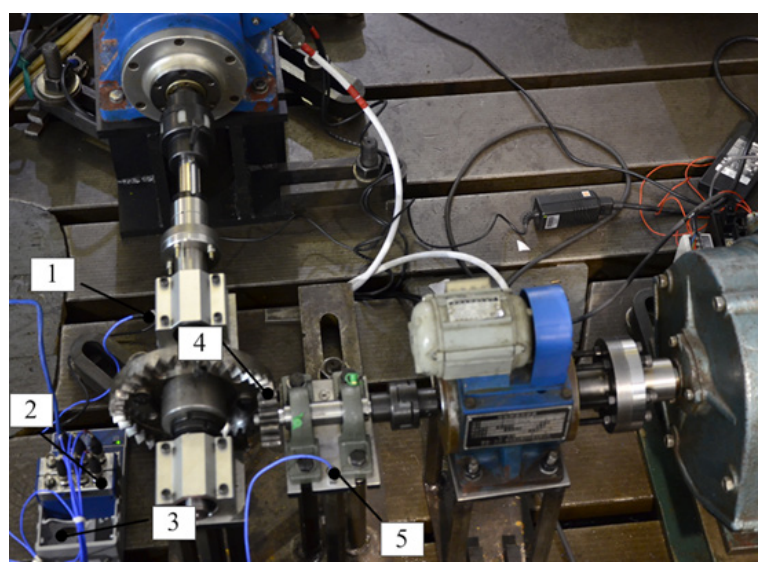

Fig. 11. Experiment platform
Dynamic signals can be acquired by measuring the vibration value along $X, Y$ and $Z$ directions on the bearing cap. No. 1 and 5 are acceleration sensors; No. 2 is the dynamic signal acquisition module; No. 3 is the Ethernet chassis. No. 4 is the simplified curve-face gear pair.

Since the acquisition process is affected by the interference of random signals, acquired data will be picked by some existing errors. To reduce the influence of the error on the experimental results, the data must be collected after certain processing. The changing rules of the vibration response along $X$ and $Y$ are the same. Therefore, the variation responses along $X$ in the meshing period were analysed as shown in Fig. 12

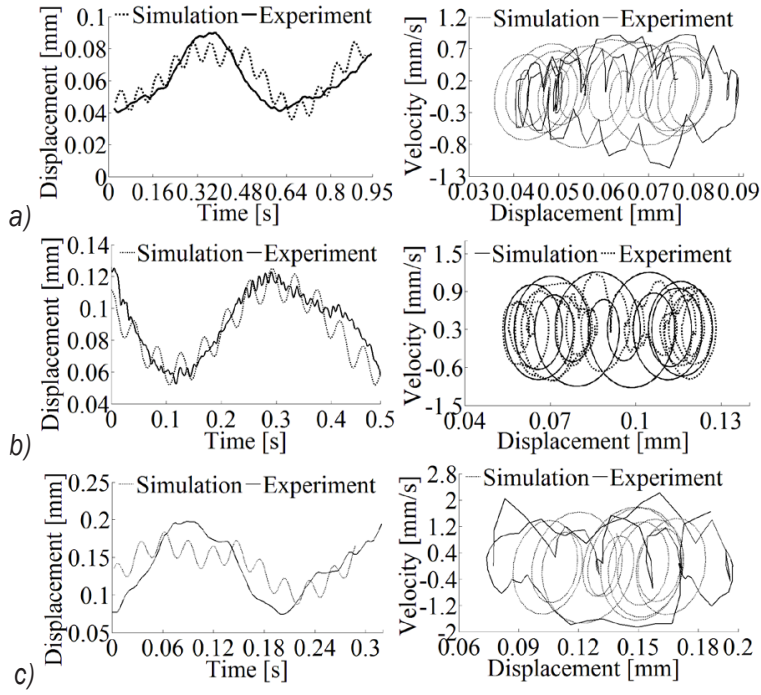

Fig. 12. The comparison between experimental and theoretical data; time history chart and phase diagram for input velocity a) $200 \mathrm{rpm}$, b) $400 \mathrm{rpm}$, and c) $600 \mathrm{rpm}$

The velocity signal (Fig. 12b) and displacement signal (Fig. 12a) can be transformed directly by the first and twice integral of the acceleration signal, separately.

The experimental results prove that:

1) when the meshing frequency is constant, the periodic fluctuation of the vibration response of the curve-face gear is more complex than that of the face gear due to the influence of the basic parameters of curve-face gear;

2) the comparison between experiment and simulation results demonstrates that the analytical results show good agreement with the related experimental data. It is reasonable to conclude that the experiment presents the validation of numerical model. 


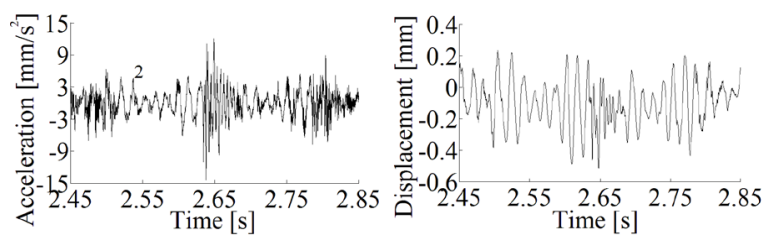

Fig. 13. Experimental result under limited speed; vibration acceleration and time history chart

For the validation of the limited speed of the curve-face gear, the vibration response can be obtained when the input speed is around $790 \mathrm{rpm}$, as shown in Fig. 13. The vibration displacement of the gear pair is negative, which indicates the reverse contact of the gear pair and will cause the destruction of the gear. Thus, the gear pair reaches the limit speed position, which represents the validation of the mathematical model.

\section{CONCLUSIONS}

1) A nonlinear dynamic model based on a Lagrange bond-graph was presented. The proposed method not only applies to the dynamic analysis of the curve-face gear, but also can be applied to the face gear.

2) The external excitation, caused by $r_{\mathrm{b} 1}$ and $R$ which are affected by the eccentric $k$ and the order $n_{1}$ of non-circular gear, is the main factor affecting the vibration response of curve-face gear. The research results show that reducing the eccentricity and raising the order number $n_{1}$ will improve the dynamic characteristics of system.

3) The vibration response of the curve-face gear is also affected by the meshing frequency. However, due to the influence of external excitation, which will exacerbate the vibration, the limited meshing frequency of the curve-face gear is lower than that of the face gear. These characteristics determine that the gear cannot be applied to the transmission system with high speed.

4) The experiment results are in good agreement with the theory analysis of the models. It is reasonable to conclude that the model presented is capable of efficiently simulating the vibration response of the curve-face gear.

\section{ACKNOWLEDGMENT}

This work supported by Research Program supported by from the National Natural Science Foundation (51275537), China and Graduate Student Research Innovation Project (No. CYB15019).

\section{NOMENCLATURES}

$R$ the radius of curve-face gear, [mm]

$r\left(\theta_{1}\right)$ the polar radius of non-cylindrical gear, $[\mathrm{mm}]$

$k$ eccentricity

$n_{1}$ the order number of non-cylindrical gear

$n_{2}$ the order number of curve-face gear

$a$ semi major axis of ellipse, $[\mathrm{mm}]$

$F_{I} \quad$ D 'Alembert force, $[\mathrm{N}]$

$\tau_{I}$ inertia force, $[\mathrm{N}]$

$F_{K}$ elastic force, $[\mathrm{N}]$

$F_{S}$ input force, $[\mathrm{N}]$

$F_{R}$ dissipative force, $[\mathrm{N}]$

$F_{k}$ elastic force caused by gear comprehensive error, [N]

$F_{r}$ dissipative force caused by gear comprehensive error, [N]

$T_{I}$ comprehensive velocity transform matrix in inertial field

$q_{G}$ displacement vector in generalized coordinates system

I mass matrix in inertial field

$T_{W}$ transform matrix of angular velocity in inertial field

$C_{C}$ rotation matrix in inertial field

$I_{C}$ inertia matrix in inertia field

$T_{K}$ velocity transform matrix in elastic field

$K$ stiffness matrix

$T_{R}$ velocity transform matrix in damping field

$R$ damping matrix

$T_{S}$ velocity transform matrix in potential source

$\tau_{S}$ input force vector

$T_{k}$ velocity transform matrix of gear comprehensive error in elastic field

$K_{e}$ stiffness matrix of gear comprehensive error

$e_{t}$ gear comprehensive error vector

$T_{r}$ velocity transform matrix of gear comprehensive error in damping field

$R_{e}$ damping matrix of gear comprehensive error

$T_{1}$ driving torque, $[\mathrm{N} \cdot \mathrm{m}]$

$T_{2}$ driven torque, $[\mathrm{N} \cdot \mathrm{m}]$

$\alpha_{n}$ pressure angle of curve-face gear, $\left[{ }^{\circ}\right]$

$r_{b 1}$ base radius of non-cylindrical gear, [mm]

$T_{V}$ translational transform matrix in inertial field

$T_{W}$ angular velocity transform matrix in inertial field

$E$ unit vector

$k_{m}$ meshing stiffness, $\left[\mathrm{N} \cdot \mathrm{m}^{-1}\right]$

$k_{m m}$ average meshing stiffness, [N $\left.\cdot \mathrm{m}^{-1}\right]$

$\Omega_{h}$ gear meshing frequency

$\varepsilon_{m}$ time-varying contact ratio

$\varepsilon_{m m}$ average contact ratio

$\sigma_{i} \quad$ initial phase

$\varepsilon_{i} \quad i$-order time-varying contact ratio 
$\omega_{n}$ nominal simulating frequency

$b_{m}$ the normal backlash, [mm]

$\eta_{j} \quad$ nominal displacement (angle) $j=(x, y, \vartheta, \lambda)$

$\tau$ nominal time

$e(t)$ dimensionless comprehensive error

$\omega_{h}$ dimensionless simulating frequency

\section{REFERENCES}

[1] Lin, C., Gong, H., Nie, N., Zen, Q., Zhang, L. (2012). Geometry design, three-dimensional modeling and kinematic analysis of orthogonal fluctuating gear ratio face gear drive. Proceedings of the Institution of Mechanical Engineers, Part C: Journal of Mechanical Engineering Science, vol. 227, no. 4, p. 779-793, DOI:10.1177/0954406212453382.

[2] Litvin, F.L., Wang, J.-C., Bossler, R.B., Chen, Y.-J., Heath, G., Lewicki, D.G. (1994). Application of face-gear drives in helicopter transmissions. Journal of Mechanical Design, vol. 116, no. 3, p. 672-676, Dol:10.1115/1.2919434.

[3] Lin, C., Cai, Z. (2015). Modeling of dynamic efficiency of curve-face gear pairs. Proceedings of the Institution of Mechanical Engineers, Part C: Journal of Mechanical Engineering Science, vol. 230, no. 7-8, p. 1209-1221, DOI:10.1177/0954406215623308.

[4] Mohammed, O.D., Rantatalo, M., Aidanpää, J.-0. (2015). Dynamic modelling of a one-stage spur gear system and vibration-based tooth crack detection analysis. Mechanical Systems and Signal Processing, vol. 54-55, p. 293-305, DOI:10.1016/J.ymssp.2014.09.001.

[5] Mohammed, O.D., Rantatalo, M., Aidanpää, J.-O., Kumar, U. (2013). Vibration signal analysis for gear fault diagnosis with various crack progression scenarios. Mechanical Systems and Signal Processing, vol. 41, no. 1-2, p. 176-195, D0l:10.1016/j. ymssp.2013.06.040.

[6] Sawalhi, N., Randall, R.B. (2014). Gear parameter identification in a wind turbine gearbox using vibration signals. Mechanical Systems and Signal Processing, vol. 42, no. 1-2, p. 368-376, DOl:10.1016/J.ymssp.2013.08.017.

[7] Khabou, M.T., Bouchaala, N., Chaari, F., Fakhfakh, T., Haddar, M. (2011). Study of a spur gear dynamic behavior in transient regime. Mechanical Systems and Signal Processing, vol. 25, no. 8, p. 3089-3101, D0I:10.1016/J.ymssp.2011.04.018.

[8] Karnopp, D. (1977). Lagrange's equations for complex bond graph systems. Journal of Dynamic Systems, Measurement, and Control, vol. 99, no. 4, p. 300-306, Dol:10.1115/1.3427123.

[9] Shen, Y., Yang, S., Liu, X. (2006). Nonlinear dynamics of a spur gear pair with time-varying stiffness and backlash based on incremental harmonic balance method. International Journal of Mechanical Sciences, vol. 48, no. 11, p. 1256-1263, Dol:10.1016/j.jijmecsci.2006.06.003.

[10] Litak, G., Friswell, M.I. (2005). Dynamics of a gear system with faults in meshing stiffness. Nonlinear Dynamics, vol. 41, no. 4, p. 415-421, D0I:10.1007/s11071-005-1398-y.

[11] Lin, T., Ran, X. (2012). Nonlinear vibration characteristic analysis of a face-gear drive. Journal of Vibration and Shock, vol. 31, no. 2, p. 25-31. (in Chinese)

[12] Li, X., Zhu,R., Li Z. (2013). Analysis of coupled vibration of face gear drive with non-orthogonal. Journal of Central South University (Science and Technology), vol. 44, no. 6, p. 22742280.

[13] Wang, A., Ma,Q., Liu, L. (2006). Modeling and Simulation of Ellipse Gears. Journal of Mechanical Transmission, vol. 30, no. 4, p. 7-10. (in Chinese)

[14] Chen,Y., Hu,Q., Luo, L. (2009). Research on a novel transmission mechanism based on the principle of space curve mesh. Journal of Mechanical Transmission, vol. 33, no. 2, p. 1-4. (in Chinese)

[15] Arakawa, A. (1995). Contact ratio of noncircular gears. Transactions of the Japan Society of Mechanical Engineers Series C, vol. 61, no. 585, p. 2093-2099, D0l:10.1299/ kikaic.61.2093. (in Japanese)

[16] Lin, C., Liu, Y., Gu, S. (2014). Analysis of nonlinear twisting vibration characteristics of orthogonal curve-face gear drive. Journal of the Brazilian Society of Mechanical Sciences and Engineering, vol. 37, no. 5, p. 1499-1505, D0l:10.1007/ s40430-014-0296-y.

[17] Wu, H., Wang, J., An, Q. (2008). Study on the calculating method of radial stiffness of tapered roller bearing. Lubrication Engineering, vol. 33, no. 7, p. 39-43. 